using tartrate-resistant acid phosphatase (TRAP) staining and bone resorption assay, respectively. Osteoblast differentiation was assessed by alkaline phosphatase staining and activity was determined by calcium measurement in the supernatant.

Results Trabecular bone volume, thickness and number as well as cortical volume and thickness, and femur length were significantly lower in 12-week-old IL-23R $\mathrm{R}^{-/-}$mice compared to WT. In addition, three-point bending data revealed reduced maximum force in IL-23R $\mathrm{R}^{-/}$femurs. Surprisingly, bone volume was similar between both groups at the age of 26 weeks. However, similar to 12 -week-old mice, endocortical volume and femur perimeter were significantly lower in $\mathrm{IL}-23 \mathrm{R}^{-/-}$mice compared to WT. To further study the temporal differences in bone phenotype, we studied osteoclasts and osteoblasts from 7- and 12-week-old mice in vitro. Osteoclast differentiation and function were similar at both ages between WT and IL$23 \mathrm{R}^{-/-}$mice. Interestingly, $\mathrm{BM}$ cells of 7 -week-old IL-23R $\mathrm{R}^{-/-}$ mice had reduced capacity to differentiate towards osteoblasts, compared to WT. In contrast, these cells showed higher differentiation and significantly higher calcium uptake than WT mice at 12 weeks.

Conclusions IL-23R ${ }^{-/-}$mice have temporally dynamic changes in bone metabolism, which is possibly related to alterations in osteoblasts, however, the exact mechanism still needs to be elucidated.

Disclosure of Interest None declared.

\section{P121/021 MIR-146A AN IMPORTANT KEY PLAYER IN BONE METABOLISM}

${ }^{1} V$ Saferding*, ${ }^{1} \mathrm{M}$ Hofmann, ${ }^{1} \mathrm{JS}$ Brunner, ${ }^{1} \mathrm{MF}$ Militaru, ${ }^{1} \mathrm{~A}$ Puchner, ${ }^{1} \mathrm{~S}$ Hayer, ${ }^{2} \mathrm{M}$ Timmen, ${ }^{2} \mathrm{R}$ Stange, ${ }^{1} \mathrm{JS}$ Smolen, ${ }^{1} \mathrm{~S}$ Blüml. ${ }^{1}$ Medical University of Vienna, Vienna, Austria; ${ }^{2}$ University Hospital Muenster, Muenster, Germany

\subsection{6/annrheumdis-2018-EWRR2019.109}

Career situation of first and presenting author Post-doctoral fellow.

Introduction Micro RNAs (miRNAs) play a crucial role in the regulation of bone metabolism. MiR-146a, an important antiinflammatory miRNA, was found to negatively impact osteogenesis and bone regeneration in vitro, by controlling the differentiation of mesenchymal stem cells. But to date the role of miR-146a in bone remodelling, its influence on bone stability and development of osteoporosis is not known.

Objectives Our aim is to analyse the function of miR-146a in bone metabolism.

Methods Systemic bone, tibiae and femur, of wt and miR146a deficient animals was assessed histologically and via $\mu \mathrm{CT}$ analysis, over a period of 3 to 18 months of age. Serum cytokine levels were analysed by Elisa. MRNA expression levels in bone were analysed by qPCR. To induce osteoporosis, ovariectomy (OVX) induced bone loss was performed.

Results When we analysed bone volume of long bones histologically as well as with $\mu \mathrm{CT}$ analysis we detected significantly increased trabecular bone mass in miR-146a deficient compared to wt animals, starting at an age of 6 months. In addition cortical thickness of systemic bones from miR-146a knock out animals was significantly increased compared to control mice. Analysis of serum in aged miR-146a deficient animals displayed elevated activity of bone resorbing osteoclasts as amounts of CTX I in miR-146 $\mathrm{a}^{-/-}$mice were significantly increased compared to wt animals. Q-PCR analysis of important osteoclast as well as osteoblast marker genes in bones ex vivo displayed elevated expression of signature molecules of both cell types in aged miR-146a deficient mice, suggesting a regulatory role of miR-146a in both osteoclasts as well as osteoblasts. When we induced osteoporosis using the OVX disease model, histological analysis of long bones showed significant trabecular bone loss in ovariectomized wt mice. In contrast, we detected no trabecular bone loss in ovariectomized miR-146a knock out animals, suggesting that loss of miR-146a deficiency protects bone loss induced by estrogen deficiency.

Conclusions MiR-146a seems to control bone turnover and miR-146a deficient mice accrue bone over time. Moreover this miRNA has a negative influence on bone loss occurring during oestrogen loss induced osteoporosis. Therefore miR146 a could be possibly used as a therapeutic target in the treatment of osteoporosis.

Disclosure of Interest None declared.

\section{P122 IMPORTANT ROLE OF DENDRITIC CELLS IN INFLAMMATORY ARTHRITIS}

${ }^{1} \mathrm{E}$ Simader*, ${ }^{1} \mathrm{~A}$ Puchner, ${ }^{1} \mathrm{~V}$ Saferding, ${ }^{1} \mathrm{E}$ Goncalves-Alves, ${ }^{2} \mathrm{R}$ Pfeifle, ${ }^{3} \mathrm{G}$ Krönke, 1J Smolen, 'S Blüml. 'Rheumatology, Medical University of Vienna, Vienna, Austria; ${ }^{2}$ Rheumatology, Universitätsklinikum Erlangen; ${ }^{3}$ Rheumatology, Universitätsklinikum Erlangen, Erlangen, Germany

\subsection{6/annrheumdis-2018-EWRR2019.110}

Career situation of first and presenting author Student for a master or a $\mathrm{PhD}$.

Introduction Important role of dendritic cells in inflammatory arthritis.

Objectives Investigation of the role of $\mathrm{CD} 11 \mathrm{c}^{+}$cells in joint inflammation and destruction.

Methods We analyzed histological sections of $\mathrm{K} / \mathrm{BxN}$ serum transfer arthritis as well as hTNFtg arthritis for the presence of $\mathrm{CD}_{11 \mathrm{c}^{+}}$cells by immunohistochemistry. We used CD11cdiphteria toxin receptor (DTR) transgenic mice. $\mathrm{K} / \mathrm{BxN}$ serum transfer arthritis was induced, and mice were given either DT or PBS or in wt and BARF3 deficient mice. In addition CD11c DTR mice were crossed into hTNFtg animals and also received either DT or PBS. The severity of arthritis was determined clinically and histologically.

Results Both $\mathrm{CD}^{+} \mathrm{CD} 11 \mathrm{c}^{+}$and $\mathrm{CD} 11 \mathrm{~b}^{+} \mathrm{CD} 11 \mathrm{c}^{+}$, can be found in synovial tissue in TNF driven arthritis. Upon depletion of $\mathrm{CD}_{11 \mathrm{c}^{+}}$cells clinical signs of $\mathrm{K} / \mathrm{BxN}$ serum transfer arthritis were significantly reduced. Histological analysis found reduced synovial inflammation after the depletion of $\mathrm{CD} 11 \mathrm{c}^{+}$ cells in $\mathrm{K} / \mathrm{BxN}$ arthritis. In addition, local bone destruction and the number of osteoclasts was also significantly reduced. In addition to $\mathrm{K} / \mathrm{BxN}$ arthritis, we found that also in TNFdriven arthritis depletion of $\mathrm{CD}_{11 \mathrm{c}^{+}}$cells led to a striking reduction of synovial inflammation and a complete depletion of osteoclasts.

Conclusions These data show that in addition to initiating an adaptive immune response, $\mathrm{CD} 11 \mathrm{c}^{+}$dendritic cells, are also involved in innate effector mechanisms of inflammatory 